\title{
Hardening Properties of Foamed Concrete with Circulating Fluidized Bed Boiler Ash, Blast Furnace Slag, and Desulfurization Gypsum as the Binder
}

\author{
Seunghyun $\mathrm{Na}^{1}$, Woonggeol Lee ${ }^{2}$, Myongshin Song ${ }^{2 *}$ \\ ${ }^{1}$ Institute of Industrial Science, The University of Tokyo, Tokyo City, Japan \\ ${ }^{2}$ Research Center of Advanced Convergence Processing on Materials, Kangwon National University, Samcheok City, Korea \\ Email: *msong0422@kangwon.ac.kr
}

How to cite this paper: Na, S., Lee, W. and Song, M. (2021) Hardening Properties of Foamed Concrete with Circulating Fluidized Bed Boiler Ash, Blast Furnace Slag, and Desulfurization Gypsum as the Binder. Open Journal of Civil Engineering, 11, 301-316.

https://doi.org/10.4236/ojce.2021.113018

Received: August 23, 2021

Accepted: September 10, 2021

Published: September 13, 2021

Copyright $\odot 2021$ by author(s) and Scientific Research Publishing Inc. This work is licensed under the Creative Commons Attribution International License (CC BY 4.0).

http://creativecommons.org/licenses/by/4.0/

\begin{abstract}
Recently, a large amount of circulating fluidized bed boiler ash (CFBA) and desulfurization gypsum (DSG) has been produced, and it is essential to develop technology to utilize them. These materials have $\mathrm{CaO}$ and $\mathrm{SO}_{3}$, which are considered to be a stimulant for blast furnace slag (BFS). This study presents an experimental investigation of the compressive strength and heavy metal ions immobilization properties of cement-free materials comprising CFBA, BFS, and DSG. The feasibility of manufacturing foamed concrete using these materials was examined, and field test of foamed concrete was conducted. Experimentally, the flow, compressive strength, and heavy metal ions concentration were evaluated via inductively coupled plasma atomic emission spectroscopy (ICP-AES) of the paste and foamed concrete. The experimental investigation revealed the self-healing hardening ability of fluidized bed boiler ash. In addition, the compressive strength was increased with the increasing replacement rates of BFS and DSG in the CFBA paste, and the compressive strength of 14.6 - 17.2 $\mathrm{MPa}$ was recorded over 28 days of curing. From the result obtained, the feasibility of manufacturing foamed concrete with a foam volume of $120 \mathrm{~L}$, incorporating the aforementioned materials, is confirmed. It was also found that after 28 days of age, a 7.9-MPa compressive strength of the foamed concrete was attained, and heavy metal ions elution in this foamed concrete was also significantly reduced. Therefore, CFBA, BFS, and DSG could be used as a binder for the foamed concrete.
\end{abstract}

\section{Keywords}

Circulating Fluidized Bed Boiler Ash, Compressive Strength, Foamed 
Concrete, Heavy Metal Ions Immobilization, Field Test

\section{Introduction}

The use of cement as a building and civil engineering material necessitates cement manufacturing that causes $\mathrm{CO}_{2}$ emission; therefore the use of various industrial by-products for reducing the use of cement has been actively investigated and implemented. In general, the industrial by-products, such as blast furnace slag (BFS), fly ash (FA), and metakaolin (MK), are used as construction and civil engineering materials, and these materials may facilitate a long-term enhancement of the strength and an improvement in the watertightness and chemical resistance.

Recently, the circulating fluidized bed boiler ash (CFBA) generated during the desulfurization process in a coal power plant has been studied during its application as a building and civil engineering material [1] [2] [3] [4] [5]. It may lead to $\mathrm{CO}_{2}$ reduction due to the reduced use of cement [5]. However, when this material is incorporated into cement, several problems have been reported [3]. In general, when it is substituted with cement, it is not easy to introduce the air contents by the unburned carbon of the CFBA, and it may cause expansion after hardening. It is considered that these problems may be related to the fundamental ingredients in CFBA. CFBA has a high content of free $\mathrm{CaO}$, and the content of $\mathrm{SiO}_{2}$ and $\mathrm{Al}_{2} \mathrm{O}_{3}$ is lower than that recommended in the ASTM and KS standards; CFBA is not suitable as a cement replacement material in concrete when a large amount of cement needs to be substituted. In addition, when the powder with a high content of free $\mathrm{CaO}$ is used directly on concrete as a binder, it may cause cracks in the concrete after hardening due to the high heat of hydration, owing to the hydration of free $\mathrm{CaO}$ and the consequent generation of $\mathrm{Ca}(\mathrm{OH})_{2}$. Therefore, it is possible that the presence of $\mathrm{CaSO}_{4}$ can cause expansion and cracking of the concrete due to the formation of ettringite. Several methods have been proposed in consideration of their material properties [5] [6] [7].

Further, CFBA has various applications: it is used for stabilizing heavy metal ions, neutralizing acid effluent from abandoned mines, and solidifying waste cavity filling. The application of coal ash to backfill has also been reported as cementless controlled low strength material [7]. This advantageous application can be attributed to the fact that CFBA exhibits a self-filling ability as a backfill material, and therefore it is easy to fill due to its high flowability, as observed in a mine-filling experiment based on controlled low strength material (CLSM) [8]-[14]. CLSM is defined by US ACI $229 \mathrm{R}$ as a material with a compressive strength of approximately $8.3 \mathrm{MPa}$, primarily used as a backfill material [8]. However, no cases of CFBA using CFBA have been reported in Korea.

The objectives of this study are to investigate the effect of the CFBA, CFBA-BFS, 
and CFBA-BFS-DSG systems on the compressive strength and heavy metal characteristics, to assess the fabrication and strength characteristics of foamed concrete based on the CFBA-BFS-DSG system in the laboratory, and to evaluate the field test of the manufactured foamed concrete based on the CFBA-BFS-DSG system.

\section{Experimental Plan}

\subsection{Materials}

Two different types of CFBA, BFS, and DSG were used in this study. The chemical compositions and physical properties of the materials used in this experiment are shown in Table 1 and Table 2, respectively. The density, Blaine fineness, and free $\mathrm{CaO}$ were measured with respect to KS L 5120. The CFBA1 and CFBA2 was produced from different periods. As shown in Table 1, CFBA2 contains more iron oxide than CFBA1, better heavy metal ion immobilization performance is expected.

Figure 1 shows the results of X-ray diffraction analysis of each material used in this study. As a result of the X-ray diffraction analysis, peaks of $\mathrm{CaO}, \mathrm{CaSO}_{4}$ and $\mathrm{Fe}_{2} \mathrm{O}_{3}$ were detected in the CFBA2, and an amorphous peak and peak of anhydrite were detected in the BFS. In addition, peaks of $\mathrm{CaO}$, Calcite, Anhydrite, and Quartz minerals were confirmed in DGS. In addition, power picture and scanning electron microscopy imaging of CFBA2 are shown in Figure 2 and Figure 3, respectively. As given in Figure 2, the color is brown since the CFBA2 contains a fairly large amount of iron oxide $\left(\mathrm{Fe}_{2} \mathrm{O}_{3}\right)$. In addition, CFBA2 has very small pores on the surface of the columnar shape by means of the scanning electron microscopy imaging of CFBA2 as shown in Figure 3 . The alkyl benzene

Table 1. Chemical compositions of raw materials used.

\begin{tabular}{ccccccccc}
\hline & \multicolumn{8}{c}{ Chemical compositions (\%) } \\
\cline { 2 - 9 } & $\mathrm{SiO}_{2}$ & $\mathrm{CaO}$ & $\mathrm{Al}_{2} \mathrm{O}_{3}$ & $\mathrm{MgO}$ & $\mathrm{K}_{2} \mathrm{O}$ & $\mathrm{SO}_{3}$ & $\mathrm{Fe}_{2} \mathrm{O}_{3}$ & $\mathrm{TiO}_{2}$ \\
\hline $\mathrm{CFBA} 1$ & 25.5 & 28.4 & 11.5 & 13.4 & 0.9 & 0.6 & 18.4 & 0.7 \\
$\mathrm{CFBA} 2$ & 27.4 & 22.3 & 12.9 & 8.8 & 0.9 & 0.8 & 25.3 & 0.8 \\
BFS & 35.2 & 38.0 & 15.7 & 4.2 & 0.3 & 5.1 & 0.3 & 0.4 \\
DSG & 2.4 & 90.0 & 0.8 & 2.3 & 0.2 & 2.9 & 0.5 & 0.2 \\
\hline
\end{tabular}

Table 2. Physical properties of raw materials used.

\begin{tabular}{ccc}
\hline & Free $\mathrm{CaO}$ & Ig. loss \\
\hline CFBA1 & 4.14 & 0.7 \\
CFBA2 & 3.46 & 0.9 \\
BFS & - & 0.8 \\
DSG & - & 0.7 \\
\hline
\end{tabular}




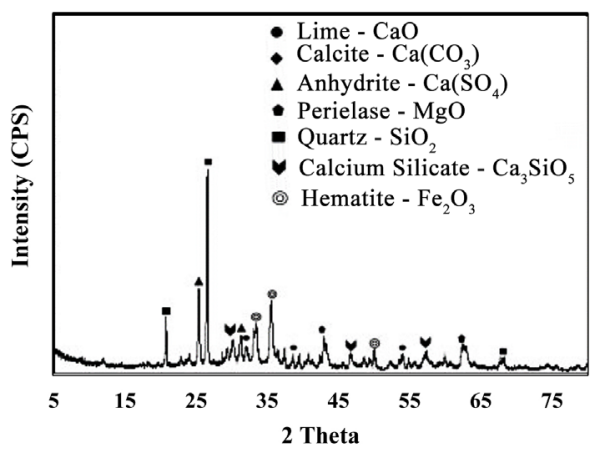

(a)

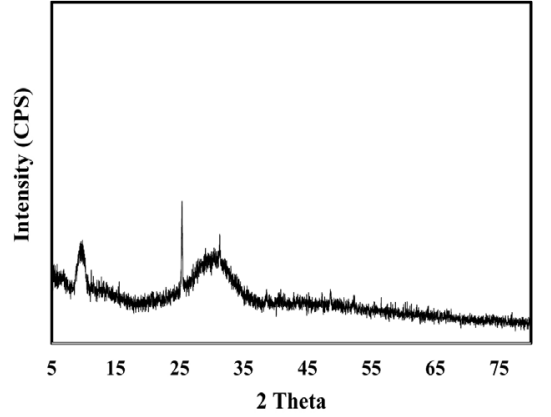

(b)

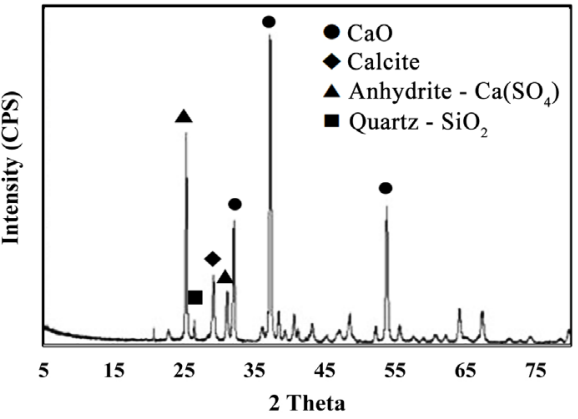

(c)

Figure 1. X-ray diffraction pattern of raw materials used. (a) CFBA2; (b) BFS; (c) DSG.

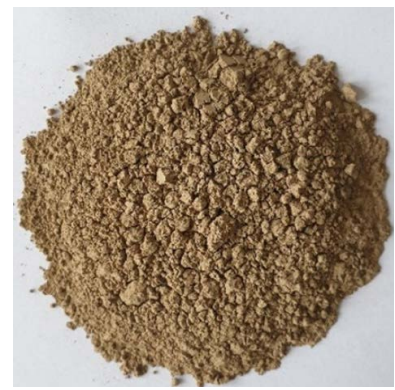

Figure 2. Raw material of CFBA2.

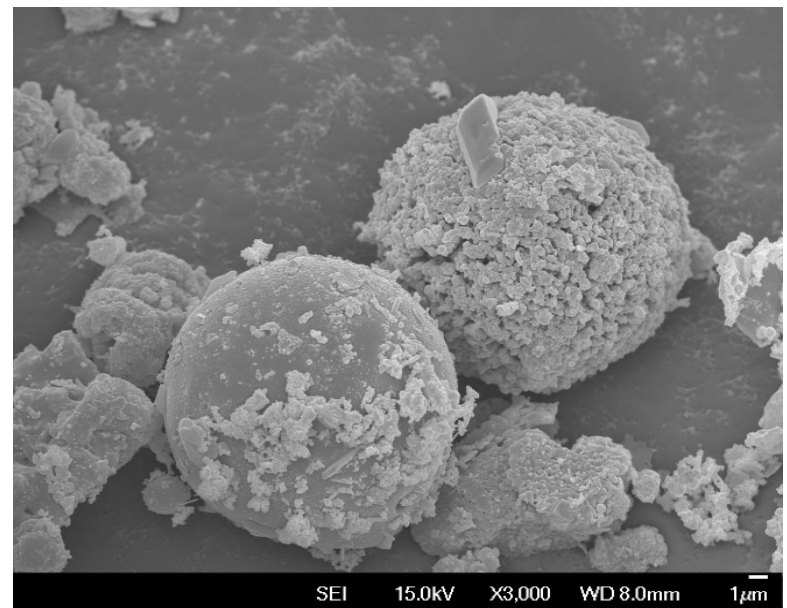

Figure 3. SEM imaging of CFBA2. 
sulfonate foaming agent also was used to manufacture the foamed concrete. Before mixing, it was mixed with water to ensure a 50:50 wt\%.

\subsection{Mixture Proportion}

The mixture proportion for paste and foamed concrete prepared using CFBA, BFS, and DSG are shown in Table 3 and Table 4, respectively. The water to binder ratio $(\mathrm{W} / \mathrm{B})$ was set at $0.65,0.8$, and 1.0 , and the replacement ratios of BFS to CFBA were 2, 5, and 10 (wt $\%$ ). The replacement ratios of DSG to CFBA-BFS system were 0,3 , and $5 \mathrm{wt} \%$ in the paste. In the manufacturing foamed concrete, W/B was 0.65 and 87:10:3 mixing proportion of CFBA2, BFS, and DSG. The foam volumes were set to $0,40,120$, and $220 \mathrm{~L}$.

\subsection{Mixing, Specimen Preparation, and Curing Condition}

All the investigated paste samples were mixed according to KS L 5109 and were poured in a $160 \times 40 \times 40 \mathrm{~mm}$ prism and placed in the laboratory for $24 \mathrm{~h}$; subsequently, they were sealed until the testing age. All the investigated foamed concrete samples $(200 \times 100 \mathrm{~mm}$ cylinder $)$ were placed in the laboratory for $24 \mathrm{~h}$ and were thereafter sealed until the testing age.

\subsection{Experimental Methods}

\subsubsection{Flow Test}

To evaluate the characteristic after mixing, flow test was conducted on the paste

Table 3. Mixture proportions of paste.

\begin{tabular}{cccccc}
\hline & & \multicolumn{3}{c}{ wt $\%$} \\
\cline { 3 - 6 } & & CFBA1 & CFBA2 & BFS & DSG \\
\hline \multirow{2}{*}{ CFBA paste } & 0.80 & 100 & & & \\
& 1.00 & 100 & & & \\
CFBA-BFS paste & 0.80 & & 98 & 2 & \\
& 0.80 & & 95 & 5 & \\
CFBA-BFS-DSG & 0.80 & & 90 & 10 & \\
paste & 0.65 & & 90 & 10 & 0 \\
& 0.65 & & 87 & 10 & 3 \\
\hline
\end{tabular}

Table 4. Mixture proportions of formed concrete.

\begin{tabular}{cccc}
\hline \multirow{2}{*}{ W/B } & \multicolumn{2}{c}{ Unit weight $\left(\mathrm{kg} / \mathrm{m}^{3}\right)$} & $\begin{array}{c}\text { Formed contents } \\
\text { (Liter) }\end{array}$ \\
\cline { 2 - 3 } & Binder & Water & 0 \\
& 400 & 320 & 40 \\
400 & 280 & 120 \\
& 400 & 200 & 220 \\
\hline
\end{tabular}


according to KS L 5111. The flow test of foamed concrete was evaluated according to KS F 4039.

\subsubsection{Compressive Strength}

The compressive strength test of the paste of foamed concrete was conducted according to KS L 5105.

\subsubsection{ICP-AES Analysis}

To confirm the heavy metal inhibitory effect of the foamed concrete, a column test was conducted as shown in Figure 4. In this experiment, a cylindrical sample with the dimensions of $100 \times 200 \mathrm{~mm}$ was used, and approximately $20 \mathrm{~mm}$ of the upper part of the foamed concrete sample was cut. Thereafter, the foamed concrete was installed inside a plastic container, and a sample taken from a mine was placed on it at a height of two $20 \mathrm{~mm}$. Thereafter, the speed was adjusted to $20 \mathrm{~cm}^{3} / \mathrm{s}$ of distilled water at the top of the cylinder. In addition, after $12 \mathrm{~h}$, the discharged water was filtered using a filter with a 7- $\mu \mathrm{m}$ mesh, and this solution was used for measuring the heavy metals via ICP-AES analysis (Varian Vista-PRO, Australia).

\section{Laboratory Test Results}

\subsection{Compressive Strength of Hardened Material Mixed with CFBA Blended System}

Figure 5 presents the results of the compressive strength for CFBA1 with

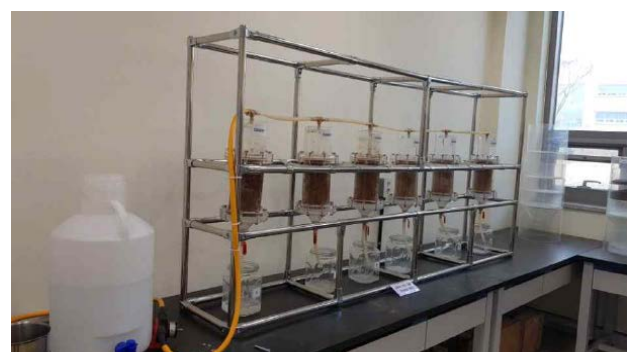

Figure 4. Column test.

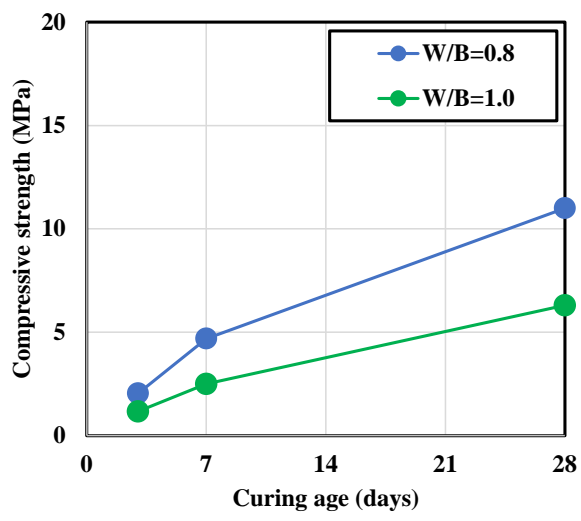

Figure 5. Compressive strength of CFBA paste only. 
different $\mathrm{W} / \mathrm{B}$, wherein the higher water to CFBA1 ratios of 0.8 and 1.0 were used to ensure workability because the fineness of CFBA1 was considerably high, as described in the material section. It can be seen from the figure that the compressive strength of the two types CFBA samples increased with the increasing curing ages, implying that CFBA exhibits a self-hardening ability and it reacts with water owing to cement hydration to produce calcium-silicate-hydrate (CSH) gel. These results agree with the findings in the previous study [2]. This can be explained based on the fact that the CFBA contains $\mathrm{SiO}_{2}, \mathrm{CaO}, \mathrm{CaSO}_{4}$, and glass phase that may cause the formation of $\mathrm{CSH}$ gel through the reaction of $\mathrm{SiO}_{2}$ and $\mathrm{CaO}$ with water, as well as ettringite through the reaction of activated alumina of gypsum and quicklime, implying the increasing strength of the CFBA paste [3]. Therefore, it is deemed that it is possible to manufacture CFBA hardened composite with a compressive strength of approximately $10 \mathrm{MPa}$ or above by actively utilizing the self-hydration properties of CFBA1, considering the reduction of the water/cement ratio and the addition of a dispersant to the cement.

\subsection{Compressive Strength of CFBA-BFS System}

Figure 6 shows the results of the compressive strength for the CFBA2 blended paste with different BFS replacement ratios of 0, 2, 5 and $10 \mathrm{wt} \%$. From the figure, it is observed that there is no clear difference between the compressive strength and BFS replacement ratio in the early curing ages of 3 and 7 days. However, for the curing age of 28 days, there is a slight increase in the compressive strength with the increasing BFS contents. This can be attributed to the use of a combination of CFBA and BFS, given the fact that BFS reacts with $\mathrm{Ca}(\mathrm{OH})_{2}$ in the CFBA to form CSH gel that implies pozzolanic behavior, resulting in a slight increase in the strength towards the later days of the curing age. In a previous study conducted by Zhang et al. [1], the strength and durability of non-cement CFBA with BFS composite were studied; the CFBA comprised of approximately $50 \%$ glass. They reported that the effect of the quality of CFBA on the compressive strength was negligible, however the effect of salt penetration was increased. Moreover, it was confirmed from the previous study that a high

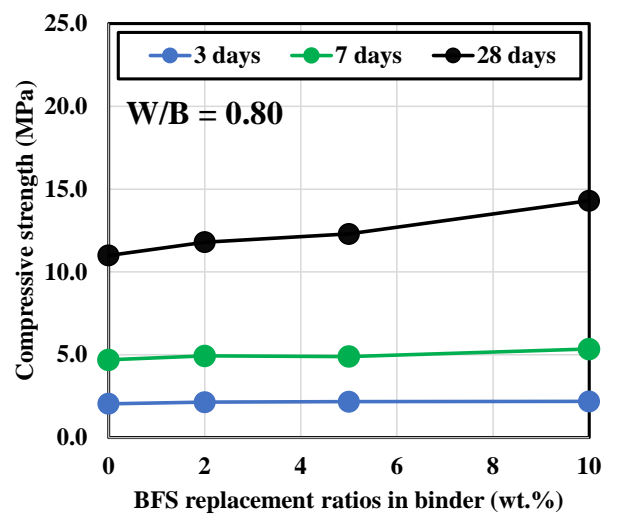

Figure 6. Compressive strength of CFBA paste with BFS. 
compressive strength was exhibited as the BFS was mixed with the CFBA [3]. Therefore, from the results of Figure 6, it could be suggested that the alkali and stimulant components in CFBA act as stimulants for the BFS with more reactive glass components, leading to the increasing compressive strength in the CFBA with the BFS system.

\subsection{Compressive Strength of CFBA-BFS-DSG}

It has been well known that BFS activates the hydration reaction in the presence of gypsum. Figure 7 shows the result of the compressive strength of the CFBA-BFS system, incorporating DSG as an industrial by-product. It can be seen from the figure that as the mixing ratio of the DSG in the contents increases, the compressive strength increases slightly, suggesting that the incorporation of DSG in the CFBA-BFS system has a positive effect on the compressive strength characteristics. The reason for this behavior is due to the fact that 1) the increasing DSG content may accelerate the hydration of the BFS, resulting in the generation of ettringite and 2) BFS reacts with $\mathrm{Ca}(\mathrm{OH})_{2}$ in the DSG and produces CSH gel with the types of low calcium silicate that are present in the CFBA-BFS-DSG system. Therefore, it is considered that the middle-level compressive strength can be controlled by combining these materials. However, the relationship between the pore structure and compressive strength of the CFBA-BFS incorporating DSG is not evident in this study; therefore, this needs to be studied further.

\subsection{Fabrication of Foamed Concrete Mixed with the CFBA-BFS-DSG System, and Evaluation of Their Compressive Strength and Fluidity}

The aim of this study is to produce foamed concrete as a filling material for mines. However, to apply the foamed concrete in the construction field, it is extremely important to evaluate the fluidity and stability of the foamed concrete before hardening. In this section, the results of examining the effect of the constituents of foamed concrete on the fluidity and compressive strength are presented, as shown in Figure 8 and Figure 9. From the results, as shown in Figure 8,

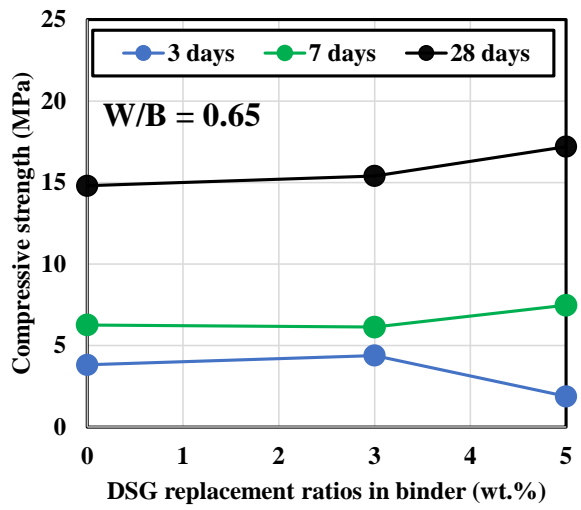

Figure 7. Compressive strength of CFBA paste with BFS. 


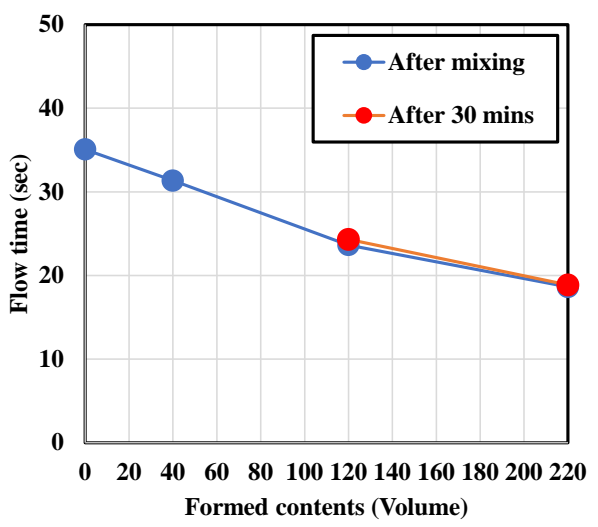

Figure 8. Influence of formed contents on flow time.

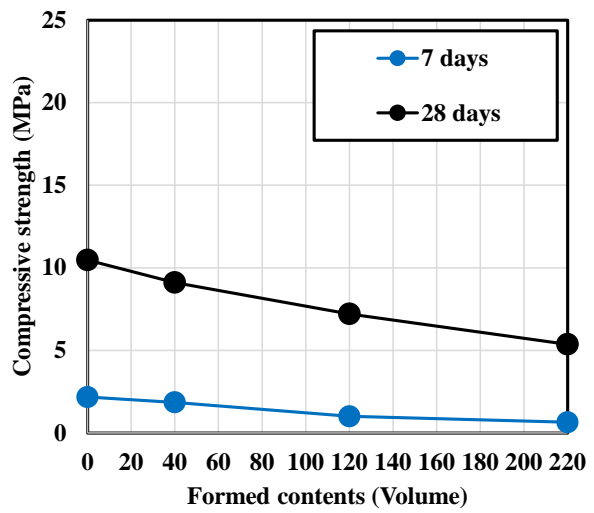

Figure 9. Influence of formed contents on compressive strength.

it can be seen that the flow time tends to decrease with the increasing formed contents. This can be explained by the fact that the hydration of binder is slightly delayed with the increasing formed volume. Particularly, in the case of the fluidity measured after $30 \mathrm{~min}$, when the amount of foamed concrete was mixed with more than $120 \mathrm{~L}$, there was no significant difference observed in the initial fluidity, suggesting an appropriate flow stability. Figure 9 shows the results of the compressive strength of the foamed concrete. The result from Figure 9 reveals that the compressive strength tends to decrease with the firmed contents; this decrease is due to incorporating a large amount of foamed concrete. From the results of the flow and compressive strength above, it is considered that a foam volume of approximately $120 \mathrm{~L}$ is suitable for the production of foamed concrete.

Table 5 shows the results of the heavy metal analysis. The heavy metal ions in the sludge collected from the mine appeared in the order of $\mathrm{Zn}>\mathrm{As}>\mathrm{Cu}>\mathrm{Pb}>$ $\mathrm{Cd}$, and it can be seen that considerable amount of heavy metal ions is present in the sludge (control). However, when the foamed concrete is incorporated in the sludge, it is obvious that the heavy metal concentration in all the investigated foamed concrete samples is remarkably reduced, compared with the sludge. This will be discussed in detail in Section 5 . 
Table 5. Analysis result of the concentrations of heavy metal by means of column test (ND: not detected).

\begin{tabular}{ccccc}
\hline \multirow{2}{*}{$\begin{array}{c}\text { Heavy metals } \\
(\mathrm{mg} / \mathrm{L})\end{array}$} & Control & \multicolumn{3}{c}{ Mixs. } \\
\cline { 3 - 5 } $\mathrm{Cu}$ & 299.7 & 0.07 & $\mathrm{~B} 2$ & $\mathrm{~B} 3$ \\
\hline $\mathrm{Pb}$ & 227.5 & 0.05 & 0.11 & 0.06 \\
$\mathrm{As}$ & 1380.4 & $\mathrm{ND}$ & $\mathrm{ND}$ & $\mathrm{ND}$ \\
$\mathrm{Cd}$ & 65.0 & $\mathrm{ND}$ & $\mathrm{ND}$ & $\mathrm{ND}$ \\
$\mathrm{Zn}$ & 7122.5 & 0.58 & 0.70 & $\mathrm{ND}$ \\
\hline
\end{tabular}

\section{Application of Foamed Concrete in Construction Field}

\subsection{Overview}

Casting of the foamed concrete was conducted in the second Yeonhwa abandoned mine located in Punggok-ri, Gagok-myeon, Samcheok-city, Gangwon-do, Korea. The dimensions of the tunnel were $2.0 \mathrm{~m} \times 2.0 \mathrm{~m} \times 10.0 \mathrm{~m}$, as shown in Figure 10. The temperature and humidity at the time of the on-site construction were $4^{\circ} \mathrm{C}-8^{\circ} \mathrm{C}$ and $40 \%$ - 60\% RH, respectively, on December 3rd, 2015.

\subsection{Construction Method}

\subsubsection{Mixing Procedure}

Figure 11 shows the equipment used in field construction. The foamed concrete with 87:10:3 mixing proportion of CFBA2, BFS, and DSG with 0.65 W/B was used, as described in Section 3.4, and the corresponding foam volume was set to $120 \mathrm{~L}$. The foamed concrete volume was $40 \mathrm{~m}^{3}$. Each of the materials mentioned above was mixed for $5 \mathrm{~min}$ and thereafter poured into a tunnel in the mine. The distance between the mixing place and the casting place was $860 \mathrm{~m}$. After mixing, the foamed concrete was poured, as shown in Figure 12 and Figure 13.

\subsubsection{Foamed Concrete Sampling and Testing Methods}

To evaluate the compressive strength and heavy metal ions concentration of the concrete produced in the field, a cylindrical mold was first produced while pouring the mixture, and subsequently, the core of the foamed concrete was collected by targeting the concrete placed in the tunnel, as shown in Figure 14. In addition, because it takes an extremely long time to evaluate the heavy metal elution characteristics in the field, in this study, to confirm the degree of elution of heavy metals, the acquired foamed concrete core was evaluated through a column test similar to that conducted in the laboratory, as discussed in Section 2. Subsequently, the concentration of heavy metal was measured via ICP-AES.

\subsection{Field Test Results}

Table 6 presents the results of the measurement of the compressive strength and heavy metal concentration for the foamed concrete on the construction site. It is 

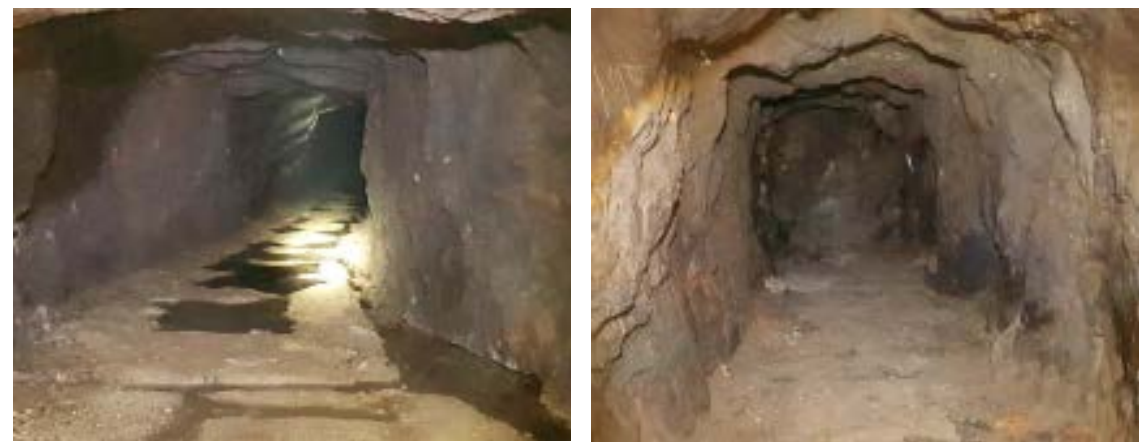

Figure 10. Tunnel in the mines.

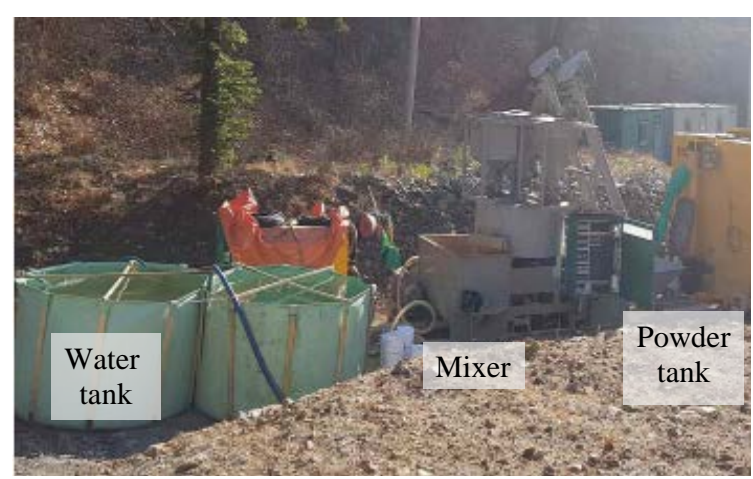

Figure 11. Equipment used in the field.

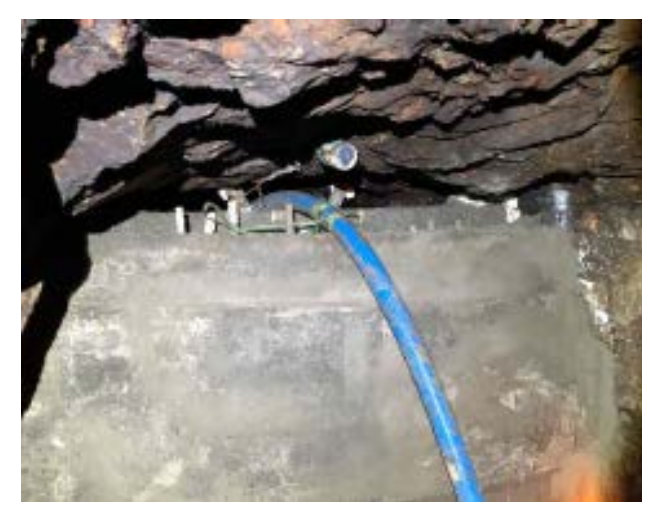

Figure 12. Introduction of formed concrete.

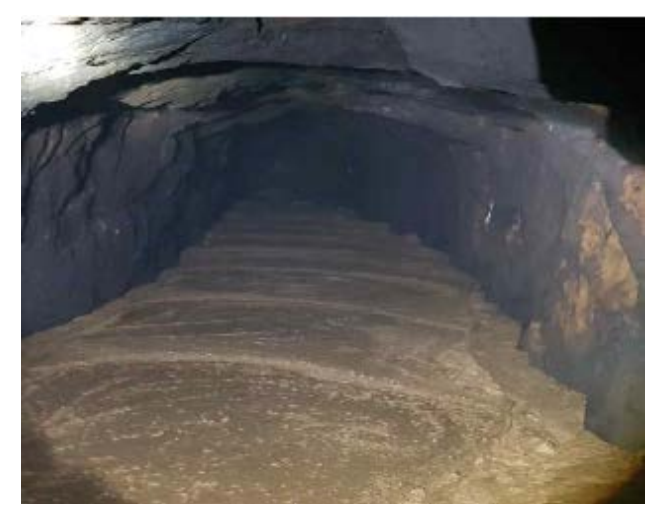

Figure 13. Formed concrete pouring. 


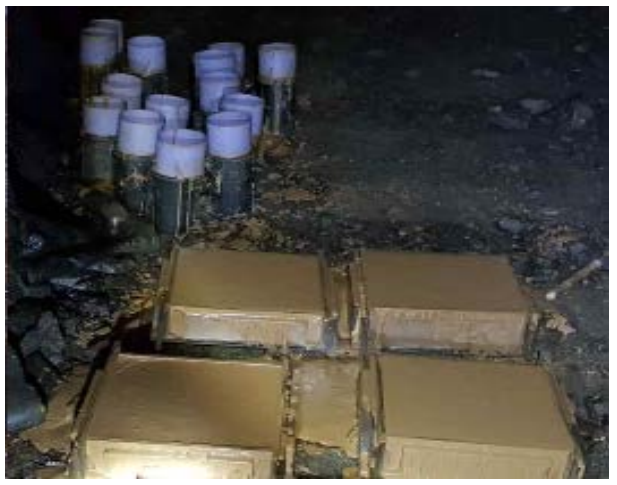

(a)

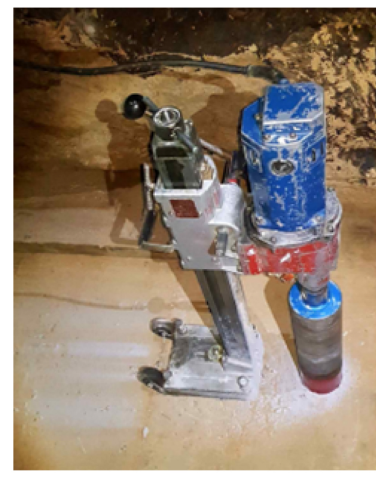

(b)

Figure 14. Fabrication of sample for evaluating the quality of the formed concrete. (a) Concrete specimens after mixing; (b) Core sampling.

Table 6. Test results of density, compressive strength, and heavy metals.

\begin{tabular}{cccc}
\hline \multicolumn{2}{c}{ Test items } & Mold & Core \\
\hline \multicolumn{2}{c}{ Compressive strength $(\mathrm{MPa})$} & 7.45 & 7.91 \\
& $\mathrm{Cu}$ & 0.063 & 0.067 \\
& $\mathrm{~Pb}$ & $\mathrm{ND}$ & $\mathrm{ND}$ \\
$\begin{array}{c}\text { Heavy metals } \\
(\mathrm{mg} / \mathrm{L})\end{array}$ & $\mathrm{As}$ & $\mathrm{ND}$ & $\mathrm{ND}$ \\
& $\mathrm{Cd}$ & $\mathrm{ND}$ & $\mathrm{ND}$ \\
& $\mathrm{Zn}$ & 0.513 & 0.537 \\
\hline
\end{tabular}

confirmed that the compressive strength of the sample poured in the cylindrical mold and core machine is 7.45 and 7.91, respectively, implying that the compressive strength is approximately $8.3 \mathrm{MPa}$, as recommended in the ACI standard [3]. Moreover, it can be seen from the results of ICP-AES analysis that the heavy metals concentration is extremely low, which agrees with results in the laboratory results. From the above results, it is confirmed that the foamed concrete mixed with CFBA, BFS, and DSG, exhibits improved compressive strength development and heavy metal immobilization effect.

From above observation, the test results revealed that the hardened composites incorporating CFBA, BFS, and DSG exhibited compressive strengths of 10 to $25 \mathrm{MPa}$ and had better immobilization performances for heavy-metal ions. Therefore, the suggested mixture proportions can be used as soil stabilizers or low-cost adsorbents to reduce leaching of the heavy-metal ions. In addition, since these materials are all industrial byproducts, it is possible to reduce the carbon dioxide generated during cement production, suggesting that this technique is an economical and a promising solution for protecting the natural environment.

\section{Solidification Mechanism of Heavy-Metal Ions}

The heavy-metal inhibition mechanism for foamed concrete material mixed 
with CFBA, BFA, and DGS is as follows. The pore structure and composition of each material used were considered along with the hydration products of the materials.

\subsection{Micropores and Iron Content of CFBA}

From the viewpoint of pore structure, the CFBA used in this study has a high specific surface area; several micropores exist in the material such that the heavy-metal ions are adsorbed into them. Therefore, this behavior can be physically correlated to reduction of the amounts of heavy-metal ions. In addition, it is seen that the content of $\mathrm{Fe}_{2} \mathrm{O}_{3}$ in each type of CFBA2 is very high at about $25 \%$, as shown in Table 1 . The peak for $\mathrm{Fe}_{2} \mathrm{O}_{3}$ (hematite) in the CFBA is identified using X-ray diffraction analysis, as given in Figure 1. Therefore, it is possible that heavy-metal ions are adsorbed by iron, and the concentration is reduced owing to formation of such iron-containing crystals with heavy-metal ions [15] [16] [17]. This formation may contribute to low concentrations of the heavy-metal ions.

\subsection{Immobilization of Heavy-Metal Components by Ettringite and C-S-H Hydrate Generation}

There is evidence in literature for experimental investigations of CFBA hydration with BFS through X-ray diffraction analysis to confirm the presence of ettringite, monosulfate, and $\mathrm{C}-\mathrm{S}-\mathrm{H}$, which are representative hydrated products [1] [2]. In the case of ettringite, the effects of immobilizing heavy-metal ions by CFBA2, BFS, and DSG are considered since the free $\mathrm{CaO}$ and $\mathrm{CaSO}_{4}$ in these materials produce the ettringites; this also suggests that ettringites may immobilize the heavy-metal-ion complex salts through ionic exchange. As reported in literature, it can be confirmed that $\mathrm{Ca}^{2+}$ and $\mathrm{Al}^{3+}$ ions constituting the ettringites immobilize heavy-metal ions by replacing them with other heavy-metal ions at each of the sites [18] [19] [20].

However, further investigations are needed to clarify the effects of these materials on immobilization of heavy-metal ions by considering the pore structures and hydration products.

\section{Conclusions}

This study investigated the compressive strength and heavy metal fixation properties of cement-free materials including CFBA, BFS, and DSG. Moreover, the feasibility of manufacturing foamed concrete containing these materials was also investigated. The following conclusions have been drawn:

1) From the experiment of the paste in the laboratory, in the case of the CFBA and water paste, it is confirmed that the compressive strength increases with the increasing curing age because it exhibits a self-hardening property. Therefore, it could be used as a non-cement material.

2) In the case of the CFBA and BFS paste, it is found that the compressive 
strength increases with the increasing curing age. Moreover, when DSG is mixed in the paste of CFBA and BFS, it is confirmed that the compressive strength is increased.

3) In the case of foamed concrete containing CFBA, BFS, and DSG, it is confirmed that the elution of a considerable amount of heavy metals is suppressed.

4) In case of the on-site foamed concrete, a comparable compressive strength is observed at 28 days of age, compared with the laboratory results, and the concentration of heavy metals is also significantly reduced.

5) In this study, it was shown that it is possible to manufacture formed concrete using CFBA, BFS, and DSG. Moreover, a further investigation on the effect of each indicator with different types of CFBA considering Blaine fineness, $\mathrm{CaO}$ and particle size distribution on basic properties in the material design stage is needed to further expand the form of concrete manufactured in the laboratory and field.

\section{Acknowledgements}

This work is supported by the Korea Agency for Infrastructure Technology Advancement (KAIA) grant funded by the Ministry of Land, Infrastructure and Transport (Grant 21CTAP-C163942-01).

\section{Conflicts of Interest}

The authors declare no conflicts of interest regarding the publication of this paper.

\section{References}

[1] Zhang, W., Choi, H., Sagawa, T. and Hama, Y. (2017) Compressive Strength Development and Durability of an Environmental Load-Reduction Material Manufactured Using Circulating Fluidized Bed Ash and Blast-Furnace Slag. Construction and Building Materials, 146, 102-113.

https://doi.org/10.1016/j.conbuildmat.2017.04.042

[2] Lee, H.-S., Kim, J.-H., Lee, J.-Y. and Chung, C.-W. (2017) Use of Flue Gas Desulfurization Gypsum as an Activator for a Ground Granulated Blast Furnace Slag. Journal of the Korea Institute of Building Construction, 17, 313-320. https://doi.org/10.5345/JKIBC.2017.17.4.313

[3] Lee, S.-H., Lee, G.-H., Yoo, D.-W., Ha, J.-H. and Cho, Y.-G. (2015) Hydration and Insulation Characteristics of a Ground Granulated Blast Furnace Slag Based Non-Sintered Cement Using Circulating Fluidized Bed Combustion Ash as a Activator. Journal of the Korea Concrete Institute, 27, 245-251. https://doi.org/10.4334/JKCI.2015.27.3.245

[4] Na, S., Kang, S., Lee, S. and Song, M. (2015) Gamma-C2S Synthesis from Fly Ash of Fluidize-Bed Boiler for $\mathrm{CO}_{2}$ Capture. Acta Physica Polonica A, 127, 1282-1285. https://doi.org/10.12693/APhysPolA.127.1282

[5] Na, S., Song, M., Kang, S., Lee, S. and Kim, K. (2015) Synthesis and Properties of Calcium Sulphoaluminate Using Fluidised-Bed Boiler Ash. Materials Research Innovations, 19, S8-779-S8-783. https://doi.org/10.1179/1432891715Z.0000000001799 
[6] Kang, Y.H., Lim, G.H., Kim, S.J. and Choi, Y.C. (2018) Feasibility Study on the Use of CFBC Ash as Non-Sintered Binder. Journal of the Korea Institute for Structural Maintenance and Inspection, 22, 119-126. https://doi.org/10.11112/jksmi.2018.22.5.119

[7] Xiao, R., Polaczyk, P., Jiang, X., Zhang, M., Wang, Y. and Huang, B. (2021) Cementless Controlled Low-Strength Material (CLSM) Based on Waste Glass Powder and Hydrated Lime: Synthesis, Characterization and Thermodynamic Simulation. Construction and Building Materials, 275, Article ID: 122157.

https://doi.org/10.1016/j.conbuildmat.2020.122157

[8] ACI Committee 229 (1999) Controlled Low-Strength Materials. ACI 229R-99. American Concrete Institute, Farmington Hills.

[9] Etxeberria, M., Ainchil, J., Pérez, M.E. and González, A. (2013) Use of Recycled Fine Aggregates for Control Low Strength Materials (CLSMs) Production. Construction and Building Materials, 44, 142-148.

https://doi.org/10.1016/j.conbuildmat.2013.02.059

[10] Do, T.M., Kim, H.K., Kim, M.J. and Kim, Y.S. (2020) Utilization of Controlled Low Strength Material (CLSM) as a Novel Grout for Geothermal Systems: Laboratory and Field Experiments. Journal of Building Engineering, 29, Article ID: 101110. https://doi.org/10.1016/j.jobe.2019.101110

[11] Fauzi, M.A., Arshad, M.F. and Md Nor, N. (2021) Statistical Models to Develop Optimised Controlled Low-Strength Materials with Wastepaper Sludge Ash. Construction and Building Materials, 286, Article ID: 122816. https://doi.org/10.1016/j.conbuildmat.2021.122816

[12] Alizadeh, V. (2019) New Approach for Proportioning of Controlled Low Strength Materials. Construction and Building Materials, 201, 871-878. https://doi.org/10.1016/j.conbuildmat.2018.12.041

[13] Manh Do, T., Kang, G.O. and Kim, Y.S. (2019) Development of a New Cementless Binder for Controlled Low Strength Material (CLSM) Using Entirely By-Products. Construction and Building Materials, 206, 576-589. https://doi.org/10.1016/j.conbuildmat.2019.02.088

[14] Wu, H., Huang, B., Shu, X. and Yin, J. (2016) Utilization of Solid Wastes/Byproducts from Paper Mills in Controlled Low Strength Material (CLSM). Construction and Building Materials, 118, 155-163. https://doi.org/10.1016/j.conbuildmat.2016.05.005

[15] Bolaños-Guerrón, D., Capa, J. and Flores, L.C. (2021) Retention of Heavy Metals from Mine Tailings Using Technosols Prepared with Native Soils and Nanoparticles. Heliyon, 7, e07631. https://doi.org/10.1016/j.heliyon.2021.e07631

[16] Ito, A., Umita, T., Aizawa, J., Takachi, T. and Morinaga, K. (2000) Removal of Heavy Metals from Anaerobically Digested Sewage Sludge by a New Chemical Method Using Ferric Sulfate. Water Research, 34, 751-758. https://doi.org/10.1016/S0043-1354(99)00215-8

[17] Shi, M., Min, X., Ke, Y., Lin, Z., Yang, Z., Wang, S., Peng, N., Yan, X., Luo, S., Wu, J. and Wei, Y. (2021) Recent Progress in Understanding the Mechanism of Heavy Metals Retention by Iron (Oxyhydr)Oxides. Science of the Total Environment, 752, Article ID: 141930. https://doi.org/10.1016/j.scitotenv.2020.141930

[18] Chen, Q.Y., Tyrer, M., Hills, C.D., Yang, X.M. and Carey, P. (2009) Immobilisation of Heavy Metal in Cement-Based Solidification/Stabilisation: A Review. Waste Management, 29, 390-403. https://doi.org/10.1016/j.wasman.2008.01.019

[19] Chrysochoou, M. and Dermatas, D. (2006) Evaluation of Ettringite and Hydrocalumite Formation for Heavy Metal Immobilization: Literature Review and Experi- 
mental Study. Journal of Hazardous Materials, 136, 20-33.

https://doi.org/10.1016/j.jhazmat.2005.11.008

[20] Gougar, M.L.D., Scheetz, B.E. and Roy, D.M. (1996) Ettringite and C-S-H Portland Cement Phases for Waste Ion Immobilization: A Review. Waste Management, 16, 295-303. https://doi.org/10.1016/S0956-053X(96)00072-4 